Research Article

\title{
A Pre-Experimental Study to Assess the Effect of Informational Booklet on Knowledge regarding Prevention of Oral Cancer among Adolescents at Selected Educational Institute of Bhopal
}

\author{
Vandana Pakhide
}

Assistant Professor, Pragyan College of Nursing Bhopal, Madhya Pradesh, India.

DOI: https://doi.org/10.24321/2348.2133.201909

I $\quad \begin{array}{lllll}\mathbf{N} & \mathbf{F} & \mathbf{O}\end{array}$

E-mail Id:

pakhidevandana@yahoo.in

Orcid Id:

https://orcid.org/0000-0002-5923-8801

How to cite this article:

Pakhide V. A Pre-Experimental Study to Assess the Effect of Informational Booklet on Knowledge regarding Prevention of Oral Cancer among Adolescents at Selected Educational Institute of Bhopal. Ind J Holist Nurs 2019; 10(2\&3): 20-26.

Date of Submission: 2019-08-29

Date of Acceptance: 2019-12-20
$\begin{array}{lllllllll}\mathbf{A} & \mathbf{B} & \mathbf{S} & \mathbf{T} & \mathbf{R} & \mathbf{A} & \mathbf{C} & \mathbf{T}\end{array}$

Oral cancer is the most common cancer in Indian male, it accounts for 50-70\% of total cancer mortality. Oral cancer is cancer of mouth or throat. Oral cancer is as twice as common in men as in women; the incidence is nearly $11 \%$ in male and $5 \%$ in female. Lack of awareness among the health care providers is the most significant factor in delaying diagnosis and treatment of oral cancer. Early detection of oral cancers makes patients more amenable to treatment and allows the greatest chance of cure.

Methods: pre-experimental research design was used for conducting study in selected educational institute of Bhopal. Subject comprising of 60 adolescents selected by non-probability convenient sampling technique, who fulfilled inclusive criteria.

Result: Mean $\pm S D$ of post-test knowledge score $(14.5 \pm 2.42)$ was higher than the Mean $\pm S D$ of pre-test knowledge score $(6.5 \pm 1.99)$. The computed ' $t$ ' value $\left(14.0^{*}\right)$ was found significant at 0.05 level and 0.01 level of significance. There was significant association found of demographic variable in terms of educational level and previous exposure to the topic.

Conclusion: It was concluded that informational booklet was effective in enhancing knowledge of adolescents regarding prevention of oral cancer. Health professionals therefore have an important role and responsibility in the prevention and early detection of oral cancer. The nurse has a significant role in early detection and treatment of oral cancer. This type of studies can help in creating awareness among general population regarding preventive strategies and modifying health behaviours.

Keywords: Oral Cancer, Informational Booklet, Prevention 


\section{Introduction}

Oral cancer is the 10th most common type of cancer contributing to death worldwide. Oral cancer is the most common cancer in Indian male, it accounts for 50-70 \% of total cancer mortality. Oral cancer is cancer of mouth or throat. Oral cancer is as twice as common in men as in women; the incidence is nearly $11 \%$ in male and $5 \%$ in female. Oral cancer is also known as oropharyngeal cancer; it is a type of head and neck cancer and is characterized by abnormal cell growth. Oral or mouth cancer most commonly involves the tongue, it may also occur on floor of the mouth, cheeks lining, gums, lips or palate (roof of the mouth). Basic etiology remains unknown, definite cause of oral cancer is unknown there are number of predisposing factors influence the development of oral cancer, such as tobacco, excessive alcohol intake, chronic irritation from a tagged tooth or poor dental hygiene and constant exposure to ultraviolet radiation from sun. ${ }^{1}$

Global health programme (2012) espouses a global focus on oral health promotions and disease prevention. Within cancer critical trial there are established criteria to monitor degrees of toxicity. Such grading criteria are only a gross indicator of the degree of toxicity and have been criticized inconsistency of variables for each level. Government of India has initiated a National Oral Health Programme to provide integrated, comprehensive oral health care in the existing health care facilities with the objectives: to improve the determinants of oral health, to reduce morbidity from oral diseases, to integrate oral health promotion and preventive services with general health care system and to encourage Promotion of Public Private Partnerships (PPP) model for achieving better oral health. ${ }^{13-14}$

Epidermal Growth Factor Receptor (EGFR) is highly expressed in several types of cancer cells including oral Squamous cell carcinoma (OSCC). ${ }^{4}$

Oral cancer at an early stage does not cause any problems and symptoms begin only in advanced stages of the disease. In the initial stages of oral cancer, the cavity is manifested as erythroplakia, a red-colored lesion or red-and-white, sharply limited by surrounding tissue. Over time, there is the development of ulcers with elevated edges. Oral cancer can also have an exophytic form, and then it is manifested by a mass that fills the oral cavity. Early signs of oral cavity cancer are red or whitish lesions of the mucous membrane that persist, a non-healing ulcer, an island or thickening of the structure of the oral cavity, atypical changes in the mucous membrane, a toothache without a clear cause, unexplained bleeding from the gingiva or nose. Late signs are induction of the affected area, paraesthesia of tongue and lips, stiffness of the jaw, dysphagia, dyspnoea, visual impairment, pain of the ears and enlarged lymph nodes on the neck. Carcinoma of the oral cavity can be detected at the earliest stage by simply examining the oral mucosa. It is important to point out that these are localizations that are accessible to the naked eye examination and visible during a regular dental examination. A timely diagnosis and treatment of oral cancer can significantly improve the prognosis and quality of life of these patients. ${ }^{2}$

Premature recognition of oral cancer allows for a $90 \%$ increase in 5-year survival rate. Unfortunately, nowadays, $60 \%$ of these tumors are detected in advanced stages with a 5 -year survival of about $20 \%$. Therefore, early detection is of greatest importance to both the General Public (GP) and the dentist, who have primary role in early diagnosis and are also responsible for improving the population's health regarding the risk factors in oral cancer. A public awareness program that stresses the importance of at least one annual dental examination, identification of warning signs of oral cancer, and recognition of hazards of tobacco and alcohol use is necessary to reverse the high morbidity and mortality rates associated with this disease. Primary prevention aims at avoiding or reducing the risk factors. Due to the motivation by various communication imparts such as personal communications, films, newspaper articles, radio programs, folk-art, posters, a great amount of the population approximating to $15 \%$ of the tobacco users have quit the use and a substantial amount of people showed reduction appreciably. As most of the oral cancers arise from precancerous lesions, the relative reduction in these lesions, have an indirect effect on the reduction of oral cancer. ${ }^{3}$

Five percent of all tumors occur in the head and neck, and approximately half of those occur specifically in the oral cavity. Of the 615,000 new cases of oral cavity tumors reported worldwide in 2000, 300,000 were primary oral cavity squamous cell carcinomas. Recent data from the Surveillance, Epidemiology and End Results Program suggest that 28,900 new cases of oral cancer will be identified and 7400 deaths attributed to oral cancer each year in the United States. The sixth leading cause of cancerrelated mortality, oral cancer accounts for 1 death every hour in the United States. However, despite advances in screening tools, imaging technology, and access to primary care physicians, a considerable percentage of patients present with advanced-stage disease. Clinical signs and symptoms of head and neck tumors are often nonspecific and may be mistaken for other common ailments. Primary care physicians must be aware of the possibility of oral cancer, particularly the increasing incidence in young patients without traditional risk factors of alcohol and tobacco abuse. To improve survival, all patients should be routinely and vigilantly screened for oral mucosal lesions. The known causes for oral mucosal problems and tumors range from infectious agents-bacterial, viral and fungal infections-to trauma sustained over a long period, as occurs 
in tobacco users from smoke inhalation, heat from burning tobacco, or specific components of the tobacco and any other substances with which it has been mixed. The effects of tobacco use appear to be exacerbated when combined with alcohol use. ${ }^{5}$

Oral cancer currently strikes about 30,000 Americans each year. Survival rates are approximately $50 \%$. However, early detection followed by appropriate treatment can increase cure rates to about $80 \%$, and greatly improves the quality of life by minimizing extensive, debilitating treatments. ${ }^{6}$

The nurse has a significant role in early detection and treatment of oral cancer, the nurse needs to provide the adolescents with information regarding predisposing factors such as constant exposure to ultraviolet sun, tobacco and other irritants. It is important that adolescents and other teenager be informed about the danger of using snuff or chewing tobacco and also teach about correct oral hygiene and dental care techniques because early detection of oral cancer is important. The person is target to report unexplained pain or soreness of the mouth, unusual bleeding, dysphagia, sore throat, voice changes and swelling or lump in the neck. Any individual with an ulcerative lesion that does not heal within 2-3 weeks should be report to a health care provider and a biopsy of the lesion should be performed. The nurse also inspects the patient's oral cavity for suspicious lesion. It is not possible to prevent all type of cancer but some cancer can be prevented by evidenced or recognized carcinogens and improving health behaviours. ${ }^{1}$

\section{Problem Statement}

A pre-experimental study to assess the effect of informational booklet on knowledge regarding prevention of oral cancer among adolescents at selected educational institute of Bhopal.

\section{Objectives}

- Assess pre-test knowledge regarding prevention of oral cancer among adolescents.

- Assess post-test knowledge regarding prevention of oral cancer among adolescents.

- $\quad$ Find out different between pre-test and post-test knowledge scores regarding prevention of oral cancer among adolescents.

- Associate pre-test knowledge scores findings regarding prevention of oral cancer among adolescents with their selected demographic variables.

\section{Research Methodology}

Research methodology indicates the general pattern of organizing the procedure for gathering valid and reliable data for investigation. In this study, quantitative research approach was adopted. Knowledge assessed by self structured questionnaire regarding prevention of oral cancer.
Research Design: In this study, pre-experimental one group pre-test post-test design was used to assess the effectiveness of informational booklet containing literature related to oral cancer.

Setting: This study is being conducted in Father Agnel Higher Secondary School.

Duration: March - April, 2019.

Sample Size: The study subjects were 60 adolescents, selected through Non- probability convenient sampling technique.

Ethical Approval: A written permission was obtained to conduct the study from the administrative authorities of the institution.

\section{Inclusion Criteria}

- Who are in the standard of $9^{\text {th }}, 10^{\text {th }}, 11^{\text {th }}$, and $12^{\text {th }}$.

- Who are in age group between 13-20 years.

- Who are present at the time of data collection.

\section{Exclusion Criteria}

- Students criteria less than the set standards.

- Students not willing to participate in the study.

\section{Development of the Tool}

- Developed informational booklet containing literature related to causes, warning signals, clinical manifestations, early diagnosis, preventive measures and healthy habit practices regarding oral cancer.

- After expert opinion developed self structured knowledge questionnaire regarding prevention of oral cancer consisting 30 items. All questions consists 4 responses. The reliability of the tool was established by Split Half Method and correlation was found by Spearmen rank order correlation formula and it was 0.87 . So it reveals that the tool is highly reliable.

- $\quad$ Scoring criteria, 1 (one) mark for correct answer and 0 (zero) for wrong answer. Categorization of score done, rating (0-10) poor, (11-20) average, and (21-30) consider good.

\section{Data Analysis Procedure}

The data obtained from 60 respondents was analysed by using descriptive and inferential statistics method after consultation of statistician, as follows:

- A master data sheet was prepared and compiled demographic data, containing selected sample characteristics was analyzed using frequency and percentage distribution.

- Data was collected and presented in the forms of tables and bar diagrams.

- Find out mean, median and standard deviation of pretest and pos- test knowledge scores. 
- $\quad \mathrm{t}$ ' test is done to find out significant difference between pre-test and post-test scores.

- Chi-square test was used to find out the association of pre-test knowledge scores with their selected demographic variables.

\section{Results}

Results in terms of objectives of the study:

1. Assess pre-test knowledge regarding prevention of oral cancer among adolescents.

Most of the sample 53.3\% were categorized in average category, $46.7 \%$ were in poor category and no one in good category.

Table I.Representing frequency and percentage distribution of pre-test knowledge score

\begin{tabular}{|c|c|c|}
\hline Pre-test scores & Frequency (N) & Percentage (\%) \\
\hline $0-10$ & 28 & 46.7 \\
\hline $11-20$ & 32 & 53.3 \\
\hline $21-30$ & 0 & 0 \\
\hline
\end{tabular}

2. Assess post-test knowledge regarding prevention of oral cancer among adolescents.

Most of the sample $63.3 \%$ were categorized in good category, $36.7 \%$ were in average category and no one in poor category.

Table 2.Representing frequency and percentage

\begin{tabular}{|c|c|c|}
\hline Post-test scores & Frequency (N) & Percentage (\%) \\
\hline $0-10$ & 0 & 0 \\
\hline $11-20$ & 22 & 36.7 \\
\hline $21-30$ & 38 & 63.3 \\
\hline
\end{tabular}

3. Find out different between pre-test and post-test knowledge scoresregarding prevention of oral cancer among adolescents.

Table 3.Representing difference between pre-test and post-test knowledge scores

\begin{tabular}{|c|c|c|c|c|c|}
\hline \multirow{2}{*}{$\begin{array}{c}\text { Sco- } \\
\text { res }\end{array}$} & \multirow{2}{*}{$\begin{array}{c}\text { Scoring } \\
\text { criteria }\end{array}$} & $\begin{array}{c}|c| \\
\text { Freque- } \\
\text { ncy (N) }\end{array}$ & $\begin{array}{c}\text { Percen- } \\
\text { tage (\%) }\end{array}$ & $\begin{array}{c}\text { Freque- } \\
\text { ncy (N) }\end{array}$ & $\begin{array}{c}\text { Percen- } \\
\text { tage (\%) }\end{array}$ \\
\hline $\begin{array}{c}0- \\
10\end{array}$ & Poor & 28 & 46.7 & 0 & 0 \\
\hline $\begin{array}{c}11- \\
20\end{array}$ & Average & 32 & 53.3 & 22 & 36.7 \\
\hline $\begin{array}{c}21- \\
30\end{array}$ & Good & 0 & 0 & 38 & 63.3 \\
\hline
\end{tabular}

Mean $\pm S D$ of post-test knowledge score $(14.5 \pm 2.42)$ was higher than the Mean \pm SD of pre-test knowledge score $(6.5 \pm$ 1.99). The computed ' $t$ ' value $\left(14.0^{*}\right)$ was found significant at 0.05 and 0.01 level of significance.

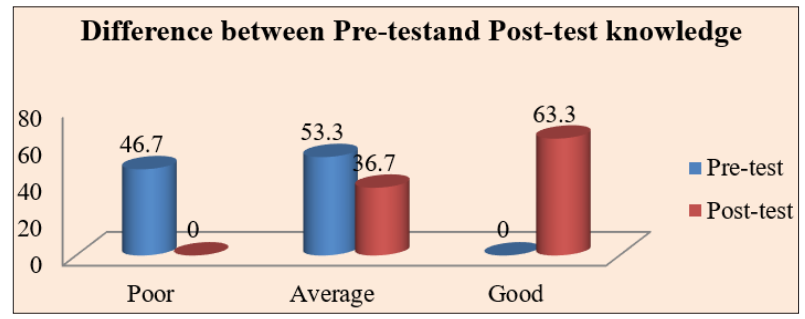

Figure I.The bar diagram representing the difference between pre-test and post-test knowledge scores

Table 4.Representing significant difference between pre-test and post-test knowledge scores

\begin{tabular}{|c|c|c|c|c|c|c|}
\hline $\begin{array}{c}\text { Sco- } \\
\text { res }\end{array}$ & Mean & Median & $\begin{array}{c}\text { Mean } \\
\text { Difference }\end{array}$ & S.D. & df & $\begin{array}{c}\text { 't' } \\
\text { value }\end{array}$ \\
\hline $\begin{array}{c}\text { Pre- } \\
\text { test }\end{array}$ & 6.5 & 7 & & 1.99 & & \\
\cline { 1 - 2 } $\begin{array}{c}\text { Post- } \\
\text { test }\end{array}$ & 14.5 & 15 & 8.0 & 2.42 & & $14.0 *$ \\
\hline
\end{tabular}

Table 5.Representing association of pre-test knowledge scores with their selected demographic variables

\begin{tabular}{|c|c|c|c|c|c|c|c|}
\hline \multirow{2}{*}{ S. No. } & \multirow{2}{*}{ Demographic variables } & \multicolumn{3}{|c|}{ Pre-test scores } & \multirow{2}{*}{ Percentage } & \multirow{2}{*}{ df } & \multirow{2}{*}{$x^{2}$} \\
\hline & & Poor & Average & Good & & & \\
\hline 1. & $\begin{array}{c}\text { Education } \\
9^{\text {th }} \text { class } \\
10^{\text {th }} \text { class } \\
11^{\text {th }} \text { class } \\
12^{\text {th }} \text { class }\end{array}$ & $\begin{array}{l}16 \\
08 \\
02 \\
02\end{array}$ & $\begin{array}{l}03 \\
07 \\
10 \\
12\end{array}$ & $\begin{array}{l}0 \\
0 \\
0 \\
0\end{array}$ & $\begin{array}{l}31.7 \\
25.0 \\
20.0 \\
23.3\end{array}$ & 6 & $16.2^{*}$ \\
\hline 2. & $\begin{array}{c}\text { Previous exposure of the topic } \\
\text { Yes } \\
\text { No }\end{array}$ & $\begin{array}{c}0 \\
28\end{array}$ & $\begin{array}{l}10 \\
22\end{array}$ & $\begin{array}{l}0 \\
0\end{array}$ & $\begin{array}{l}16.7 \\
83.3\end{array}$ & 2 & $10.3^{*}$ \\
\hline
\end{tabular}


4. Associate pre-test knowledge scores findings regarding prevention of oral cancer among adolescents with their selected demographic variables.

There was significant association found of demographic variable in terms of educational level and previous exposure of the topic, about age, gender, religion and type of family there were no association found.

\section{Discussion}

There was significant association found of demographic variable in terms of educational level and previous exposure of the topic, about age, gender, religion and type of family there were no association found. The effectiveness of informational booklet was assessed by comparing the both pre-test and post-test scores by ' $\mathrm{t}$ ' test and it was found $14.0^{*}$ is highly significant.

Findings of the study are consistent with the study conducted by Araraquara regarding knowledge on oral cancer among dentistry students at Federal University of Maranhão. A questionnaire on oral cancer was applied to 150 students from six classes, divided into three groups according to their semesters. The variables studied were statistically analyzed by applying the chi-square test with confidence interval of $95 \%$ and significance level of 5\%. Eighty-eight students (60.61\%) considered their level of knowledge on oral cancer good and regular, while $37.93 \%$ rated their knowledge as insufficient. Squamous cell carcinoma was listed as the most common cancer by only $38.25 \%$ of students, with the highest percentage of correct answers being observed for groups 2 (55.56\%) and 3 (67.39\%). The level of knowledge on the risk factors increased over the semesters; however, $77.85 \%$ considered their level of confidence to perform diagnostic procedures low. The level of knowledge on oral cancer was considered good or regular among dentistry students, and although they showed good level of knowledge on the risk factors and to specific issues of the disease, there is a clear need to implement continued educational measures throughout the course to consolidate learning on this disease. ${ }^{12}$

Shimpi N, Jethwani M, Bharatkumar A, conducted a cross sectional survey on patient awareness/ knowledge towards oral cancer and concluded that patients recognized links between tobacco and OC (Oral cancer) risk but demonstrated lower knowledge of other causal factors. Strategic patient education by providers could increase awareness of OC risk. Patients who smoked $>20+$ cigarettes per day were more knowledgeable about tobacco and OC risk compared to non-smokers and those who smoked $\leq 19$ cigarettes/ day $(p=0.0647)$. Patients who were alcohol consumers exhibited higher knowledgeability surrounding increased $\mathrm{OC}$ risk with alcohol and tobacco exposures compared to alcohol abstainers $(p=0.06){ }^{7}$
Vikas Fotedar, Shailee Fotedar, Manish Gupta, Kavita Manchanda, and Mukesh Sharma conducted a crosssectional questionnaire study on Oral Cancer. Knowledge, Attitudes and Practices: among 186 undergraduate medical students between the third to fifth years in Indira Gandhi Medical College, Shimla. The questionnaire consisted of 15 questions, five each on knowledge, attitudes and practices. The data were analysed by Statistical Package for the Social Sciences version. ${ }^{16}$ Test used were t-test, Chi-square and ANOVA. The response rate of the study was $96.5 \%$. The mean knowledge percent of the sample was good. Mean knowledge percent was higher in females than males. Higher percentage of students in $5^{\text {th }}$ year (internship) had excellent knowledge. The knowledge and practices about risk factors was not satisfactory. One hundred and twenty four (66.6\%) of the subjects disagreed/ strongly disagreed that their knowledge regarding the prevention and detection of oral cancer is current adequate. One hundred and seventy six and $(94.6 \%)$ agreed/ strongly agreed that there is need for additional training/ information regarding oral cancer. It can be concluded that though the mean knowledge of the population was good but the knowledge and practices about risk factors had to be reinforced among these students so that they can help the patients in tobacco and alcohol cessation and contribute in prevention of oral cancers. ${ }^{8}$

Avinash Jnaneswar, et al. assessed the Knowledge, Attitude, and Practices (KAPs) regarding oral cancer among private Medical Practitioners (MPs) and private dental practitioners (DPs). A cross-sectional, questionnaire-based study was conducted among $334 \mathrm{MPs}$ and 201 DPs in Bhubaneswar. A self-designed, close-ended questionnaire containing 28 items was delivered to the practitioners in their clinics. Correlation between KAP among MPs and DPs was done by Karl Pearson's correlation coefficient test. Student's t-test was used to compare the KAP among the practitioners. Of the 535 practitioners approached, 513 filled the questionnaire with a response rate of $95.88 \%$. Significantly, the mean knowledge index was higher among DPs (10.96 \pm 1.85$)$. The attitude index was higher in the MPs $(6.89 \pm 1.11)$, and the practice index was higher among the DPs (4.95 \pm 0.91$)$. The study puts forward the need of further training for both MPs and DPs to increase awareness and to strengthen their abilities to diagnose potentially cancerous intra-oral lesions. ${ }^{9}$

Farhat Kazmi, Shahad Alkait et al. conducted cross-sectional study at Princess Nourah Bint Abdulrahman University and its affiliated hospital. A total of 332 participants filled a close-ended online questionnaire. Responses to the questionnaire were analyzed using descriptive and analytical statistics. 450 health care professionals approached, 332 filled the questionnaire with a response rate of 73.77 . $\%$. It was observed that the mean knowledge index was higher among dental participants (10.96 \pm 1.85$)$. The attitude 
index was higher at medical side $(6.89 \pm 1.11)$, and the practice index was also higher among the dental participants (4.95 \pm 0.91$)$. Most of the health care professionals had knowledge regarding risk factors associated with Oral Squamous Cell Carcinoma (OSCC). The study puts forward, the need for intensive training and workshops for awareness and improvement of the abilities of the HCPs, (including dental and medical undergraduate students along with practitioners and specialists) to diagnose Oral Squamous Cell Carcinoma. ${ }^{10}$

\section{Limitations}

The study was limited to:

- $\quad$ Short time duration for data collection.

- Teenagers, between age group 13-20 years.

\section{Conclusion}

Oral cancer is a foremost health dilemma in several regions of the world. General dental practitioners and general medical practitioners play a major role in recognition of oral mucosal changes that may lead to malignancy. ${ }^{11}$ Oral cancer is a multi-factorial disease of high incidence worldwide and considered a public health problem, in which prevention and early diagnosis are the best ways to reverse this situation. ${ }^{12}$

There was significant relation found between informational booklet and knowledge score regarding prevention of oral cancer. The obtained ' $t$ ' value 14.0 * is higher than the table value, this indicates effectiveness of informational booklet. It was concluded that informational booklet was effective in enhancing knowledge of adolescents regarding prevention of oral cancer.

\section{What the Study adds to the Existing Knowledge?}

This type of studies can help in creating awareness among general population regarding preventive strategies and modifying health behaviours, such as identification of warning signs of oral cancer. The nurse has a significant role in early detection and treatment of oral cancer. It is important that adolescents and teenagers be informed about the danger of using snuff or chewing tobacco and also teach about correct oral hygiene and dental care techniques because early detection is important. If we provide illustrative informational mode to the students as well as in the community so the burden of the disease can be minimized.

\section{Recommendation}

On the basis of the findings of the study, it can be recommended that the following study can be undertaken to strengthen the health promotion behaviours.

- A similar study can be conducted with large sample with different setting.

- A similar study can be replicated on a sample with different demographic characteristics.

- A comparative study can be conducted among adolescents at selected educational institutions.

Funding: No funding sources.

Ethical Approval: This study was approved by the Institutional Ethics Committee.

\section{Conflict of Interest: None}

\section{References}

1. Lewis S, Margart HM, Brien DSO, Bucher L. Medical surgical Nursing. (7th ed). Mosby: Elsevier 2009; 10061009.

2. Heidari A. Introduction: Oral Cancer: Incidence and Management. Journal of oral cancer \& research. DOI: 10.36959/915/573.

3. Mangalath $U$, Aslam SA, Khadar AHKA, Francis PG, MikachaMSK, Kalathingal JH. Recent trends in prevention of oral cancer. J Int Soc Prev Community Dent 2014; 4(Suppl 3): S131-S138. DOI: 10.4103/22310762.149018.

4. Yoshimoto S, Morita H, Matsuda M. NFAT5 Promotes oral Squamous cell carcinoma progression in a hyperosmotic environment. Lab Invest 2020. https:// doi.org/10.1038/s41374-020-00486-1.

5. Kademani D. Oral cancer. Mayo Clinic Proceedings 7, July 2007; 878-887. https://doi.org/10.4065/82.7.878.

6. Silverman S. Early diagnosis of oral cancer. 1988. from: https://doi.org/10.1002/1097-0142(198810 15)62:1+<1796::AID-CNCR2820621319> 3.0.CO;2-E.

7. Shimpi N, Jethwani M, Bharatkumar A et al. Patient awareness/knowledge towards oral cancer: a crosssectional survey. BMC Oral Health 2018; 18(86). from: https://doi.org/10.1186/s12903-018-0539-x

8. Fotedar V, Fotedar S, Gupta M, Manchanda K, Sharma M. Oral Cancer Knowledge, Attitudes and Practices: A Survey of Undergraduate Medical Students in Himachal Pradesh, India 2015. DOI: 10.7860/JCDR/ 2015/12752.6406.

9. Jnaneswar A, Goutham BS, Pathi J, Jha K, Suresan V, Gunjan Kumar. A Cross-sectional Survey Assessing Knowledge, Attitude, and Practice Regarding Oral Cancer. 2017; 38(2): 133-139. DOI: 10.4103/ijmpo. ijmpo_107_16.

10. Kazmi F, Alkait S, Alghamdi H, Alhussain G, Tabassum A. Assessing Knowledge, Attitude and Practices for Oral Squamous Cell Carcinoma among Health Care Professionals in Princess Nourah University, Riyadh, KSA Knowledge, Attitude and Practices for OSCC. Asian Pac J Cancer Prev 2020; 21(2): 539-545. DOI:10.31557/ APJCP.2020.21.2.539

11. Awan KH, Khang TW, Yee TK, Zain RB. Assessing oral cancer knowledge and awareness among Malaysian 
dental and medical students. 2014; 903-907 DOI: 10.4103/09731482.138011.

12. Araraquara. Knowledge on oral cancer among dentistry students at Federal University of MaranhãoJan./ Feb. 2015. from: https://doi.org/10.1590/1807-2577. 1057.

13. Brunner, Suddarth's. Textbook of Medical-Surgical Nursing. 13th edition, pp.1240. ISBN- 13: 978-1-45114666-0.Wolters kluwer Publications.

14. Yarbro $\mathrm{CH}$. Margaret Hansen Frogge \& Michelle Goodmon. Cancer symptom management. $2^{\text {nd }}$ edition, 333-334. Jones \& Bartlett Publishers. 